\title{
Zinc Deficiency in Autism: A Controlled Study
}

\section{Abstract}

Autism Spectrum Disorder (ASD) is a neurodevelopmental disorder characterised by impaired socialisation and restricted and repetitive patterns of behaviour. Zinc deficiency has previously been reported in patients with ASD. A retrospective controlled trial of serum zinc levels in patients with ASD vs. non-ASD controls was undertaken to explore the potential presence of zinc deficiency in the ASD population. 72 patients with ASD were compared with 234 non-ASD controls. Serum zinc levels were compared between groups and correlations analysed for age, sex, supplement use and diet. Serum chromium and manganese levels were also compared between ASD and control groups to assess general micronutrient status. Further analysis was undertaken in the ASD group investigating potential correlations between serum zinc levels and immune function. $86 \%$ of patients with ASD were found to be zinc deficient versus $24 \%$ of the non-ASD control group. There was a mean difference of serum zinc levels between the ASD and non-ASD groups of $1 \cdot 75 \mu \mathrm{mol} / \mathrm{I}(P<0 \cdot 001, \mathrm{Cl} 1 \cdot 2-2 \cdot 1)$. There was no effect of age or sex on serum zinc levels in either the ASD or control groups. There was no significant difference in chromium or manganese levels between the ASD and control group. These results suggest zinc deficiency is likely to be common in ASD patients and is a potentially modifiable environmental factor associated with the condition. Zinc's potential role in the aetio-pathogenesis and disease evolution is discussed, and the need to consider zinc status in patients with ASD is highlighted.

Keywords: Autism; Zinc; Lymphocytes; Neurodevelopment

Abbreviations: AP-1: Activator Protein 1; ASD: Autism Spectrum Disorder; CDC: Centre for Disease Control; CNS: Central Nervous System; EED: Environmental Enteric Dysfunction; ESR: Erythrocyte Sedimentation Rate; GABA: GammaAminobutyric Acid; NFAT: Nuclear Factor of Activated T-Cells; NMDA: N-Methyl-DAspartate; SEM: Standard Error of Mean; VOCs: Volatile Organic Chemicals

Received: July 15, 2019; Accepted: July 26, 2019; Published: August 09, 2019

\section{Goyal DK ${ }^{1,2}$, Neil JR ${ }^{3}$, Simmons $\mathrm{SD}^{4}$, Mansab F ${ }^{3}$, Benjamin $\mathrm{S}^{3}$, Pitfield $\mathrm{V}^{3}$, Boulet $\mathrm{S}^{3}$ and Miyan JA ${ }^{1 *}$}

\author{
1 Faculty of Biology, Medicine and \\ Health, Division of Neurosciences and \\ Experimental Psychology, The University \\ of Manchester, UK \\ 2 Department of Medicine, St Bernard's \\ Hospital, Gibraltar, British Overseas \\ Territory \\ 3 Centre for Nutrition Education and \\ Lifestyle Management (CNELM), London, \\ UK \\ 4 Division of Medicine, University College \\ London (UCL), London, UK
}

\section{*Corresponding author: Dr. Daniel K Goyal \\ Æ danielgoyal@doctors.net.uk}

Faculty of Biology, Medicine and Health, Division of Neurosciences and Experimental Psychology, The University of Manchester, UK.

Tel: $+359301-81433$

Citation: Goyal DK, Neil JR, Simmons SD, Mansab F, Benjamin S, et al. (2019) Zinc Deficiency in Autism: A Controlled Study. Insights Biomed Vol.4 No.3:12

\section{Introduction}

There is increasing efforts to understand the etio-pathogenesis, pathologies and evolution of Autism Spectrum Disorder in a concerted effort by the scientific community to provide prevention, harm-reduction and treatment modalities for what can be a debilitating neurological disease. Within these efforts there are several insights worth considering from the body of scientific investigations [1-3].

1. ASD is a multi-factorial disease.

2. There is significant variation in outcome.

3. The condition is highly heterogeneous.
Whilst it is expected that there are multiple factors leading to the development of ASD, there remains the possibility of identifying independent risk factors, and preventing the disease, reducing the severity and/or reducing the burden of disease. Exploring cofactor metabolism and micronutrient deficiency has previously proved successful in reducing rates of other developmental disorders, with notable examples being the identification of maternal iodine deficiency as the major cause of congenital hypothyroidism and folate supplementation as a preventative intervention for Neural Tube Defects. It is worth noting that prior to the introduction of prenatal folate supplementation and folic acid fortification of foods, heritability for Neural Tube Defects was around $70 \%$ [4]. Exploring general health parameters in 
patients with ASD, such as nutrient status is also useful in the attempt to reduce the burden of co-morbid illness.

\section{Epidemiology of autism}

Recent evidence suggests a high level of disability in affected individuals, with $60-75 \%$ achieving poor or very poor outcomes in adulthood [5]. Case detection rates continue to increase. The Centre for Disease Control (CDC) reported a prevalence of 1 in 110 eight year olds in 2006 (Prevalence of autism spectrum disorders - Autism and Developmental Disabilities Monitoring Network, USA, 2006. 2009), a rate of 1 in 88 in 2008(Prevalence of autism spectrum disorders--Autism and Developmental Disabilities Monitoring Network, 14 sites, United States, 2008. 2012) and a rate of 1 in 68 in 2010 (Prevalence of autism spectrum disorder among children aged 8 years - autism and developmental disabilities monitoring network, 11 sites, USA, 2010. 2014). Early twin studies suggested a predominant genetic component; however, these studies had weak power $[6,7]$. Indeed, both studies reported a $0 \%$ dizygotic twin rate. A more recent twin study published was well designed and of high statistical power. The study concluded: environmental factors have a strong causative role in autism [8].

\section{Environmental factors in autism}

Evidence for modifiable environmental risk factors in ASD is significant. Gardner et al. undertook a recent meta-analysis exploring prenatal and maternal risk factors in the development of autism. Whilst significance was found in several domains, the need for further, more extensive studies was apparent. Possible risk factors identified included advanced maternal and paternal age at birth, maternal gestational bleeding, gestational diabetes, being first born vs. third or later, maternal prenatal medication use, and maternal birth abroad [9].

Xenobiotic exposure has recently been reviewed in detail and a strong correlation was found for autism risk and air pollution, pesticides and volatile organic chemicals (VOCs). Air pollution is worthy of considerable note, given the increasing evidence for the effects of air pollution on cognitive impairment and neurobehaviour; immunotoxicity; neurotoxicity; autonomic effects and autism specifically [10-29].

Zinc: Zinc is the second most abundant metal in the human body (second only to iron). It is essential for cellular life. Closely associated with DNA, zinc is a rate-limiting co-factor in hundreds of enzymatic processes including the polymerases underpinning protein synthesis generally [30]. At this basic level zinc is involved in gene expression and epigenetic mechanisms, and as such zinc deficiency can manifest across a diverse range of body processes, depending on individual genetic factors.

Beyond the biochemical functions of zinc (not limited to co-factor metabolism), zinc has a biophysical role throughout the body. Zinc-finger motifs are proteins, often configuring cell receptors, where zinc has a crucial role in allowing functional folding to occur, thus permitting the receptor function [31].

Zinc has also gained increasing attention for its role in cellsignaling [32,33]. Zinc has been demonstrated to provide immune and nervous system signaling, inducing $T$ cell proliferation and activation, as well as mediating NMDA and GABA receptors centrally [34,35].

Zinc is predominately found in meat, fish, dairy, nuts and grains. Absorption is dependent on the digestion of proteins to release the mainly protein bound zinc, and the passage of zinc to the jejenum without microbial uptake or binding with inhibitors. The absorbed zinc transiently increases plasma zinc levels prior its incorporation into the extravascular space with the greatest quantity of zinc being present in bone and skeletal muscle with high concentrations being found in brain, testes, skin, kidney, liver and placenta $[36,37]$. Whilst zinc is considered a non-stored essential element, the extravascular pool serves as a form of zinc storage with the majority of zinc being bound to proteins such as albumin. During times of shortage a reduction in faecal loss occurs, followed by release of zinc from bone, skeletal muscle, and other organs through a shifting pool homeostatic mechanism. Bone appears to have greater resilience to zinc deficiency, and failure of bone growth is typically a late feature of marked zinc deficiency [36]. The most recent national nutritional survey calculated average zinc levels in 4 to 18 years of age to be $14.7 \mu \mathrm{mol} / \mathrm{I}[38]$.

Zinc deficiency in early life: There have been limited human trials with prenatal zinc supplementation, the majority of studies beginning zinc supplementation during gestation. Prenatal zinc supplementation has been shown to improve autonomic function in children versus controls, and this improvement was noticeable during gestation [39-41]. Maternal zinc deficiency has been shown to increase obstetric complications and zinc deficiency may be involved in the increased obstetric risk associated with higher maternal age in a low socioeconomic group [42,43]. A recent meta-analysis of zinc supplementation given during gestation demonstrated a statistically significant reduction in preterm labour [44]. The meta-analysis included only one study where supplementation began prenatally. A recent Cochrane review of zinc supplementation on mental and motor function in children also found a low number of high-power studies and substantial study differences [45]. Of the 12 studies included, none supplemented zinc prenatally or maternally, and only two studies followed up beyond 13 months of age $[46,47]$.

Zinc and immune function: The role of zinc and the effect of zinc deficiency on the immune system has been investigated in several reviews [48-52]. It has been suggested that under chronic zinc deficiency conditions the adaptive immune system is less efficient and dependence on the innate immune system occurs, despite the innate immune system also suffering impairment under zinc deficiency conditions [49-52]. Neutrophils appear sensitive to zinc deficiency with impaired production, recruitment and phagocytic function. The cascade to adaptive immunity is also sensitive to zinc, with zinc deficiency causing impaired T-cell and B-cell production, reduced cytokine signaling and ultimately impaired function.

With the general shift to a Th2 response, impaired phagocytosis, reduced antibody production and the reduced cell-mediated messaging that occurs with zinc deficiency, it is of little surprise 
that zinc supplementation is utilized as a first line augmentation in the management of diarrheal illnesses and respiratory infections worldwide (Table 1). Zinc has been reported to be antiinflammatory, and zinc deficiency to increase pro-inflammatory cytokines (Bonaventura et al. 2014) and to increase central nervous system (CNS) inflammasome activity [53].

Zinc and the Nervous System: Zinc and the nervous system has been reviewed recently [54,55]. It is useful, given zinc's many functions, to consider the three broad categories: structure, cellsignaling and enzymatic co-factors. Zinc is a required co-factor for DNA and RNA polymerases, histone catalyses and DNA ligase. As such, zinc is involved in most aspects of protein synthesis within the CNS, and is an independent factor involved in gene expression [56]. More recently zinc has been identified as a key component in structural proteins such as zinc-finger motifs [54]. These ubiquitous proteins often form the structure of receptors such as the oestrogen, thyroid hormone and glucocorticoid receptors in the brain [57]. The presence of zinc within these proteins allows folding and the formation of the functional structure of such receptors [58]. The effects of zinc deficiency on zinc-finger motifs, and whether zinc is liberated from such proteins under chronic zinc deficiency, remain unknown.

$10-20 \%$ of CNS zinc is considered free, and is largely present pre-synaptically, and more often in the glutamenergic neurons. The release of zinc has been shown to modulate post-synaptic receptors including NMDA, GABA and voltage-gated calcium channel receptors. Zinc is essential to normal brain development.

Zinc has been implicated in olfactory, cerebellum and hippocampal development, and even mild zinc deficiency has been shown to affect memory and learning [59-62]. It has also been demonstrated that transient gestational zinc deficiency can affect memory and learning that persists into adulthood [63].

Zinc and Autism: Zinc has been examined in autism (Table 2). The lack of population based longitudinal studies hampers the generalisations to the aetio-pathogenesis of ASD. Taken together the studies conducted do though suggest zinc deficiency may be common in ASD.

\section{Methods}

Serum zinc levels were identified in 72 unique individual patients attending neurodevelopmental outpatient clinics. The inclusion criteria for cases in the study was male and female patients under 16 with a confirmed diagnosis of ASD without a previous confirmed diagnosis of zinc deficiency or evidence of treatment with zinc replacement therapy. The notes of the patients were individually scrutinized to ensure only those with a confirmed diagnosis of ASD were included in the study. The files were also analyzed to ascertain whether a previous diagnosis of zinc deficiency had been made and whether the patient was or had been on zinc replacement therapy - such individuals were excluded from analysis.

Case files were further analyzed for immune related parameters i.e., differential white cell count, ESR and platelets, to ascertain if zinc status influenced immune function in ASD patients. Plasma
Table 1 Summary of previous studies exploring a relationship between zinc and immune function.

\begin{tabular}{|c|c|c|}
\hline $\begin{array}{c}\text { Immune Cell } \\
\text { Neutrophil } \\
\text { Granulocytes }\end{array}$ & Effect of zinc deficiency & Study \\
\hline $\begin{array}{c}\text { Neutrophil } \\
\text { Granulocytes }\end{array}$ & Impaired recruitment & 60 \\
\hline $\begin{array}{c}\text { Neutrophil } \\
\text { Granulocytes }\end{array}$ & Reduced total number & 61 \\
\hline Neutrophil & Impaired Phagocytosis & 65,62 \\
\hline Monocytes & Altered cytokine production (TNF- & 74 \\
\hline B-lymphocytes & alpha \& IL-6) & 73 Reduced total count \\
\hline B-lymphocytes & Impaired antibody production & 68 \\
\hline T-cell & Impaired development (in thymus) & 71 \\
\hline T-cell & Impaired peripheral function & 72 \\
\hline T Cell & Altered cytokine signalling & $40,67,73$ \\
\hline T-Cell & Altered LPS activation pathway & 38 \\
\hline CD-8 & Impaired proliferation & 72 \\
\hline Natural Killer Cell & Reduced Activity & 63,66 \\
\hline Natural Killer Cell & Reduced total count & 64,67 \\
\hline
\end{tabular}

manganese and chromium levels were also recorded as a method of recording general nutrient status. A control group was extracted from general outpatient clinics. Following exclusion of those over 16 years of age, the control group consisted of 234 individual patients analyzed in the same time period as the ASDcohort. These results were analyzed in SPSS.

Measurement of serum zinc levels were completed via the standardized Gas Chromatography Mass Spectrometry methodology via a routine clinical laboratory.

\section{Statistical Analysis}

Differences between the case and control groups were analyzed using a standard homoscedastic unpaired 2-tailed T-Tests, unless there was statistically significant evidence that the standard deviations were different: This was determined using Levene's Test. If evidence of hereroscedasticity was found, then Welch's T-Test assuming unequal variances was used to better estimate p-values and confidence intervals. Parametric analysis was used over non-parametric analysis as the sample-size of the control and experimental groups make it reasonable to expect that the standard error of the mean-difference between groups should be normally distributed. Additionally, a multivariable analysis was conducted to investigate the effect of age and sex on zinc status. This was conducted using a Factorial ANOVA as the data did not meet the criteria for an ANCOVA analysis.

A hypothesis generating investigation of the relationship between zinc status and white-cell count was undertaken in the case group. Correlations were analysed across the entire ASD case group and in sub-groups determvned by nutritional status. These were analysed both parametrically and non-parametrically using Pearson's and Spearman's correlations respectively as it is unclear in this instance, due to smaller sample sizes of subgroups, whether the conditions for parametric analysis were met. 
Possible confounding due to age, sex, dietary factors and nutritional supplementation in the case group was also undertaken to see if these impacted zinc levels or white blood cell counts.

\section{Results}

After applying exclusion criteria there were 72 ASD cases and 234 controls. In the ASD group mean age was 7.0 yrs. of age (range 2-16) and in the control group was $10.1 \mathrm{yrs}$. of age (range 2-16). Male to female ratio in the ASD group was 3.8 and in the control group was 1.3. The ASD-cohort had a mean plasma zinc level of $10.01 \mu \mathrm{mol} / \mathrm{L}$ (SD $1.52 \mu \mathrm{mol} / \mathrm{L}$ ) and the case controls had a mean plasma zinc level of $11.76 \mu \mathrm{mol} / \mathrm{L}$ (SD $2.14 \mu \mathrm{mol} / \mathrm{L}$ ). The ASD-cohort had a significantly reduced plasma zinc level than controls (Mean Difference $=1.75 \mu \mathrm{mol} / \mathrm{L}, P<0.0001 \mathrm{Cl} 1.2$ to 2.3 ). The results withstood correction for age and sex. There were no significant differences between ASD and controls in relation to Manganese or Chromium (Table 3).

Box whisker plots show the distributions of zinc, chromium and manganese in the ASD-group in comparison to controls (Figure 1). Mean lymphocyte count in the ASD cohort was $3.68 \times 10^{-}$ $9 / \mathrm{L}$ (SD 1.6). There was a significant correlation between total lymphocyte count and plasma zinc levels when zinc was over
$10.5 \mathrm{umol} / \mathrm{l}$ in the ASD cohort $(P<0.04)$. When zinc fell below $10.5 \mu \mathrm{mol} / \mathrm{L}$ there was no direct correlation with lymphocyte count, although lymphocyte count was lower generally at a mean of $3.23 \times 10^{-9} / L$ (SD 1.8).

\section{Confounders}

Factorial ANOVA was used to determine whether Age or Sex had an effect on mineral status. There are no statistically significant interaction between case/control group and age; case/control and sex; and case/control, age and sex for zinc (Table 4).

Of the 72 patients in the ASD-cohort, 41 patients had reliable medical records of whether the patient was following a glutenfree diet or a gluten-containing diet. Of these, 22 patients were at the time of blood analysis maintaining a gluten-free diet, 19 were not. Zinc did not differ significantly between the two groups (gluten-free diet $=9.96 \mu \mathrm{mol} / \mathrm{I}$ (SEM 0.36), not gluten-free diet $=9.74 \mu \mathrm{mol} / \mathrm{I}$ (SEM 0.36)). Lymphocyte count was higher in the gluten-free group versus the not gluten free group $(4.68 \times 10$ /L, SEM 0.54 vs. $3.02 \times 10^{-9} /$ L, SEM 0.37).

Of the 72 patients in the ASD-group, 41 patients had reliable record of presence or absence of a dairy-free diet. 24 patients were on a dairy-free diet at blood analysis. Zinc did not differ significantly between the dairy-free and not dairy free groups $(9.75 \mu \mathrm{mol} / \mathrm{l}$

Table 2 A summary of previous studies exploring a relationship between zinc and autism.

\begin{tabular}{|c|c|c|c|c|c|c|}
\hline Sample & Number & \multicolumn{2}{|c|}{ Results } & \multicolumn{2}{|c|}{ Comments } & Study \\
\hline $\begin{array}{l}\text { Hair and } \\
\text { nail }\end{array}$ & 95 (50 controls) & \multicolumn{2}{|c|}{$\begin{array}{c}\text { Low Zinc correlated with Low Functioning Autism. } \\
\text { Zinc levels in hair and nails correlated with CARS } \\
\text { scores. }\end{array}$} & \multicolumn{2}{|c|}{$\begin{array}{c}\text { Authors noted higher variability of zinc levels in ASD } \\
\text { vs. controls. }\end{array}$} & 86 \\
\hline Serum & $\begin{array}{l}37 \text { (patients with } \\
\text { Phelan-McDermit } \\
\text { Syndrome) }\end{array}$ & \multicolumn{2}{|c|}{$\begin{array}{l}\text { Zinc deficiency correlated with attention deficit } \\
\text { and hyperactivity and seizures }\end{array}$} & \multicolumn{2}{|c|}{$\begin{array}{l}\text { Authors also undertook transgenic work } \\
\text { demonstrating alteration of ProSAP/Shank levels, and } \\
\text { alterations in cerebellum and hippocampal volumes. }\end{array}$} & 87 \\
\hline Plasma & $\begin{array}{l}79 \text { ASD \& } 18 \\
\text { controls }\end{array}$ & \multicolumn{2}{|c|}{ No correlation identified } & \multicolumn{2}{|c|}{$\begin{array}{l}\text { Limited details on controls, and samples were not } \\
\text { fasting. }\end{array}$} & 88 \\
\hline $\begin{array}{l}\text { Hair and } \\
\text { Urine }\end{array}$ & $\begin{array}{l}25 \text { ASD \& } 25 \\
\text { controls }\end{array}$ & \multicolumn{2}{|c|}{$\begin{array}{l}\text { Zinc hair levels were significantly lower in the ASD } \\
\text { group. }\end{array}$} & \multicolumn{2}{|c|}{ Limited participant numbers. } & 89 \\
\hline $\begin{array}{l}\text { DNA- } \\
\text { samples }\end{array}$ & $\begin{array}{l}761 \text { low verbal } \\
\text { autism ASD }\end{array}$ & \multicolumn{2}{|c|}{$\begin{array}{c}\text { ZNF804A SNP was associated with Low Verbal } \\
\text { Autism. }\end{array}$} & \multicolumn{2}{|c|}{$\begin{array}{c}\text { Analysis of zinc associated transporter. No zinc } \\
\text { analysis was conducted }\end{array}$} & 90 \\
\hline Serum & 230 ASD & \multicolumn{2}{|c|}{$\begin{array}{l}20.4 \% \text { deficient } \\
50.8 \% \text { in lower ten percent of mean normal values }\end{array}$} & \multicolumn{2}{|c|}{ Study lacked control group. } & 91 \\
\hline Hair & 1967 ASD & \multicolumn{2}{|c|}{$\begin{array}{c}50 \% \text { under } 3 y r s \text { had zinc levels below } 2 \text { SD versus } \\
30 \% \text { of all ASD children analysed }\end{array}$} & \multicolumn{2}{|c|}{$\begin{array}{l}\text { High numbers, and age correlation significant. Lack of } \\
\text { controls. }\end{array}$} & 92 \\
\hline Plasma & $\begin{array}{l}102 \text { ASD \& } 18 \\
\text { controls }\end{array}$ & \multicolumn{2}{|c|}{$\begin{array}{l}\text { Zinc deficiency correlated with hyperactivity and } \\
\text { fine motor skills impairment. }\end{array}$} & \multicolumn{2}{|c|}{ Limited controls. } & 93 \\
\hline Hair & $44 \mathrm{ASD}$ & \multicolumn{2}{|c|}{$\begin{array}{l}50 \% \text { were deficient for zinc. } \\
\text { Zinc negatively correlated with fear and } \\
\text { nervousness and verbal communication. }\end{array}$} & \multicolumn{2}{|c|}{ Low participant numbers and lack of controls. } & 94 \\
\hline Serum & $\begin{array}{l}60 \text { ASD vs. } 60 \\
\text { Controls }\end{array}$ & \multicolumn{2}{|c|}{$\begin{array}{l}\text { Zinc levels were significantly lower in the ASD } \\
\text { group. }\end{array}$} & \multicolumn{2}{|c|}{$\begin{array}{l}\text { Zinc: Copper ratio was associated with symptom } \\
\text { severity on CARS }\end{array}$} & 95 \\
\hline \multicolumn{2}{|c|}{ Variables } & ASD group ( $n=72)$ & Control Group ( $N=234)$ & Difference (umol/l) & \multicolumn{2}{|c|}{ Significance (Confidence Interval) } \\
\hline \multicolumn{2}{|c|}{$\begin{array}{c}\text { Zinc } \\
\text { (serum levels as umol/l) }\end{array}$} & 10.01 & 11.76 & 1.75 & \multicolumn{2}{|c|}{$\begin{array}{c}P<0.001 \\
(\mathrm{Cl}: 1.2-2.2)\end{array}$} \\
\hline \multicolumn{2}{|c|}{$\begin{array}{l}\text { Chromium } \\
\text { (serum levels as umol/l) }\end{array}$} & 15.26 & 16.42 & 1.16 & \multicolumn{2}{|l|}{$\begin{array}{c}P=0.20 \\
(\mathrm{Cl},-0.6-2.9)\end{array}$} \\
\hline \multicolumn{2}{|c|}{$\begin{array}{c}\text { Manganese } \\
\text { (serum levels as umol/l) }\end{array}$} & 14.69 & 14.48 & -0.21 & \multicolumn{2}{|l|}{$\begin{array}{c}P=0.77 \\
(\mathrm{Cl}-1.6-1.2)\end{array}$} \\
\hline
\end{tabular}


Table 4 Comparison of zinc status (and other plasma minerals and white cells) in ASD patients adhering to a gluten-free diet ( $n=22$ ) and ASD patients not following a gluten-free diet $(n=19)$, dairy-free diet $(n=24)$ and not dairy-free diet $(n=17)$, and those on supplements ( $n=18)$ and those not on supplementation $(n=23)$. Standard deviations are in brackets. WCC: White Cell Count.

\begin{tabular}{|c|c|c|c|c|c|c|}
\hline Variables & $\begin{array}{l}\text { Gluten-free } \\
(\mathrm{n}=22)\end{array}$ & $\begin{array}{l}\text { Not gluten-free } \\
\qquad(n=19)\end{array}$ & Dairy-free ( $n=24)$ & $\begin{array}{c}\text { Not dairy-free } \\
\quad(n=17)\end{array}$ & Supplements ( $n=18$ ) & $\begin{array}{l}\text { No supplements } \\
\qquad(n=23)\end{array}$ \\
\hline \multirow{2}{*}{$\begin{array}{c}\text { WCC } \\
\left(\times 10^{-9} / L\right)\end{array}$} & 8.89 & 8.14 & \multirow{2}{*}{$8.63(3.87)$} & \multirow{2}{*}{$8.42(3.94)$} & 9.13 & 8.09 \\
\hline & (3.74) & $(3.80)$ & & & $(3.87)$ & (3.65) \\
\hline \multirow{2}{*}{$\begin{array}{l}\text { Lymphocyte } \\
\text { Count } \\
\left(\times 10^{-9} / \text { L) }\right.\end{array}$} & 4.68 & 3.02 & \multirow[b]{2}{*}{$4.34(2.66)$} & \multirow[b]{2}{*}{$3.31(1.57)$} & 4.59 & 3.38 \\
\hline & $(2.55)$ & $(1.63)$ & & & $(2.49)$ & $(2.05)$ \\
\hline \multirow{2}{*}{$\begin{array}{c}\text { Zinc } \\
\text { (umol/l) }\end{array}$} & 9.91 & 9.74 & \multirow{2}{*}{$9.75(1.51)$} & \multirow{2}{*}{9.95 (1.59) } & 9.95 & 9.75 \\
\hline & (1.61) & (1.45) & & & (1.74) & (1.38) \\
\hline \multirow{2}{*}{$\begin{array}{l}\text { Manganese } \\
\text { (umol/l) }\end{array}$} & 17.12 & 12.37 & 17.11 & 11.79 & 17.72 & 12.96 \\
\hline & (6.55) & (3.83) & (6.60) & (2.59) & (7.56) & (3.29) \\
\hline \multirow{2}{*}{$\begin{array}{l}\text { Chromium } \\
\text { (umol/l) }\end{array}$} & 15.40 & 13.84 & 15.42 & 13.62 & 14.87 & 14.54 \\
\hline & (3.63) & $(3.80)$ & (3.60) & (3.79) & $(2.72)$ & $(4.44)$ \\
\hline
\end{tabular}
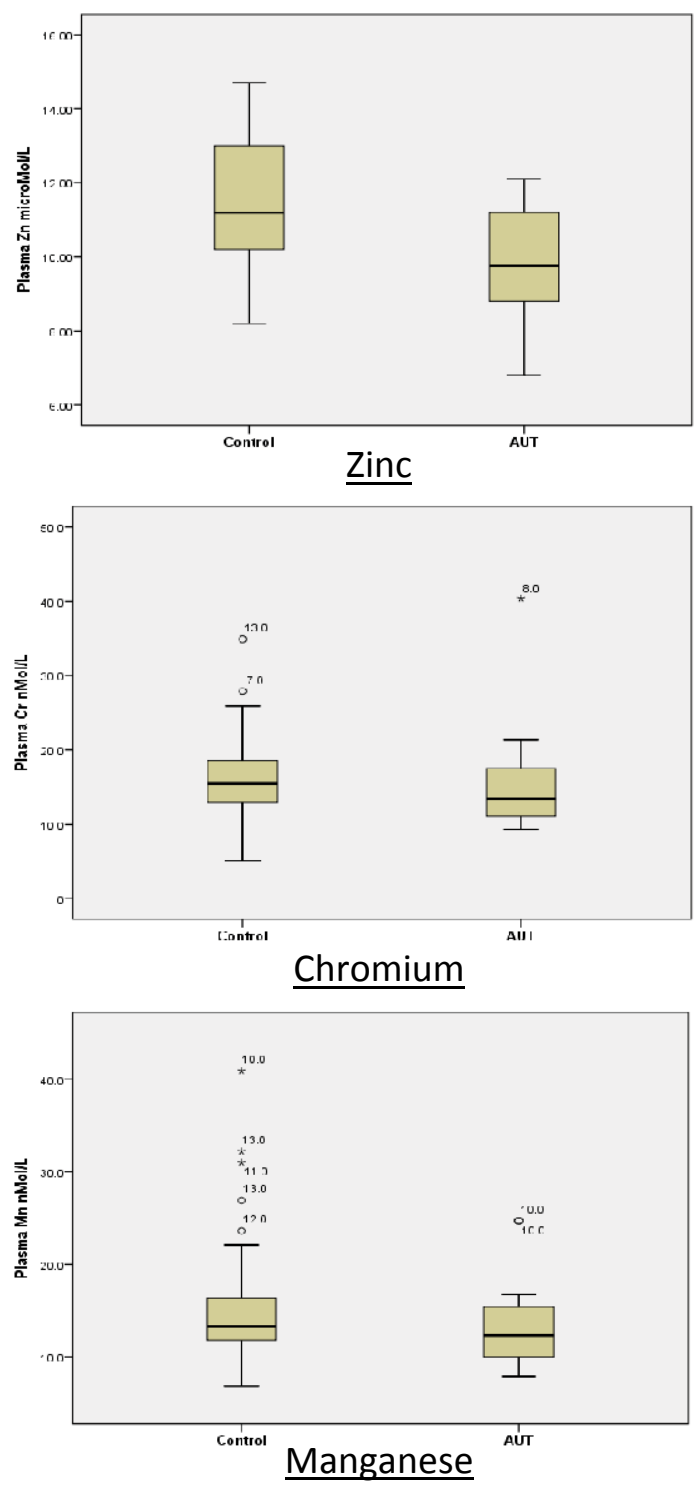

Figure 1 Box-whisker plots of serum zinc, chromium and manganese levels in ASD group ( $n=72)$ and control group $(n=234)$.
SEM 0.31 vs. $9.95 \mu \mathrm{mol} / \mathrm{I}$ SEM 0.4). Again, lymphocyte count was higher in the dairy-free group than the not dairy-free group (4.34 $\times 10^{-9} /$ L, SEM 0.34 vs. $3.31 \times 10^{-9} /$ L, SEM 0.38).

Of the 72 patients in the ASD-cohort, 41 had reliable record of supplement usage. 23 were taking nutritional supplementation. Zinc levels did not differ greatly between the supplemented and non-supplemented groups $(9.95 \mu \mathrm{mol} / \mathrm{I}$ SEM $0.42 \mathrm{vs}$. $9.75 \mu \mathrm{mol} / \mathrm{I}$ SEM 0.29). Plasma manganese was significantly higher in the supplemented group (17.72 $\mu \mathrm{mol} / / \mathrm{SEM} 1.83 \mu \mathrm{mol} / \mathrm{l}$ vs. 12.96 umol/I SEM $0.69 \mu \mathrm{mol} / \mathrm{l})$.

\section{Discussion}

The current study examined plasma zinc levels in patients with ASD in comparison to a control group. Overall, $82 \%$ of patients with ASD were classified as deficient (< $11.5 \mathrm{umol} / \mathrm{L}$ ), $57 \%$ had plasma zinc levels below 10.5 umol/L and over $25 \%$ had zinc levels below $8.80 \mathrm{umol} / \mathrm{L}$. The low plasma zinc level appeared to be having systemic effects with lymphocytes correlating with zinc levels above $10.5 \mathrm{umol} / \mathrm{L}(P<0.04)$, and below $10.5 \mathrm{umol} / \mathrm{I}$ total lymphocyte count was lower than the group mean, and lower than the population mean $(P<0.04)$.

In comparison to unhealthy controls, patients with ASD had significantly lower plasma zinc levels $(10.01 \mu \mathrm{mol} / \mathrm{L}$ vs. 11.67 $\mu \mathrm{mol} / \mathrm{L} \quad(P<0.0001)$. The findings withstood correction for age and sex, and zinc levels in those with or without dietary modification or supplementation were similar. Zinc deficiency is likely common in autism. Whether such deficiency is integral to the pathophysiology, or indeed aetio-pathophysiology, or is a consequence of chronic illness remains unknown.

\section{Is zinc deficiency a risk factor for the development of autism?}

Given the diverse role of zinc throughout the body, zinc deficiency could go some way to explain the myriad of biological findings already identified in autism. Immune, neurological and gastrointestinal abnormalities have been reported in both prenatal/perinatal and infant zinc deficiency and reported separately in autism, and there is considerable symptom overlap. 
Immune function: Whilst zinc is known for its effects on immune function, our understanding of the extent and nature of prenatal, perinatal and infantile zinc deficiency on immune function in humans remains limited. Wong et al. describe specific immune effects of prenatal zinc deficiency in a transgenic model following a maternal immune insult suggesting prenatal zinc deficiency may lead to epigenetic and immune effects responsible for maintaining a chronic inflammatory response [64]. Further transgenic work suggests that under zinc deficient conditions lysosomes containing inflammatory mediators lose integrity leading to a pro-inflammatory environment [65]. Such chronic inflammatory response has been reported in the elderly in response to zinc deficiency with an improvement of inflammatory cytokines following zinc supplementation [66]. Specifically, microglial activation has been reported in-vitro in response to zinc deficiency and reported in-vivo in patients with autism [67-70]. In animal models zinc has conferred protection against LPS induced maternal insult preventing aberrant behavior in object recognition tasks preventing abnormal sickness behaviour following immune challenge and has recently been demonstrated to prevent communication deficits in an autism mouse model [71-73]. From an immunological standpoint, developing a zinc-based intervention may provide protection or reduce the harm associated with prenatal, maternal and paternal factors contributing to the development of autism.

Neurological function: Neurological findings in zinc deficiency suffer similar limitations as immune findings. There are limited studies investigating the effects of prenatal, paternal or maternal zinc deficiency on neuropathological processes in human offspring. In a transgenic zinc deficiency model impaired glutathione metabolism was reported, perhaps explaining the protective effect of zinc supplementation on spatial and object memory following a maternal ethanol insult [74]. A significant reduction in transcription factors crucial for cell differentiation and synaptic plasticity (AP-1, NF-KB and NFAT) were reported in an experimentally induced zinc deficiency [75]. Abnormalities of the cerebellum have been reported following postnatal zinc deficiency, specifically abnormal metabolism of Purkinje cells [76]. Cerebellum abnormalities including excess Purkinje cell loss in autism have been reviewed recently [77]. Numerous environmental insults can alter glutathione metabolism, levels of transcription factors and neuronal cell loss. Perhaps then, zinc deficiency lowers the threshold for such environmental insults to lead to long-term neurodevelopmental disorders such as autism. Transgenic models have provided some evidence to suggest this may be the case. Pesticide induced neuropathology of the cerebellum and cerebrum was successfully reduced when zinc supplementation was given immediately following a 4-week exposure, and neuro-behavioural abnormalities also improved [78]. 4-months of lithium-induced cerebrum and cerebellum lipid peroxidation was reduced following 4-months of zinc supplementation with improved levels of Glutathione-Stransferase [79]. Zinc administered together with a sub-acute organophosphate exposure over three days conferred complete protection over abnormalities in the Forced Swimming Test versus no zinc supplemented controlled exposure. There was also a corresponding protection against lipid peroxidation and impaired glutathione metabolism in the cerebral cortex, and protection against impaired glutathione metabolism in the hippocampus [80]. Zinc conferred a similar protective effect against aluminiuminduced damage to the blood brain barrier in an acute toxic insult model [81]. Following ten weeks of postnatal protein restriction, 3 weeks of zinc supplementation improved oxidative stress markers and neuro-behavioural deficits - specifically locomotor activity and memory and learning [82]. Zinc provided significant protection against lead-induced neurotoxicity in a mouse model of postnatal and adult sub-acute insults via a reduction in oxidative stress and improvement in monoamine metabolism $[83,84]$. As yet, there are no studies exploring whether zinc confers a neuroprotective effect over exposure to air pollution or volatile organic chemicals.

Gut microbiomes: Zinc has been shown essential to microbiota composition and maternal zinc deficiency has even been hypothesised to influence the development of the gastrointestinal tract in autism leading to an impaired gut-brain connectivity $[85,86]$. Beyond the immune and neurological effects of zinc deficiency discussed above, and the impact such effects will have on the normal mechanisms for microbiota regulation, there are some direct microbiological effects of zinc. It appears that certain species of microbiota tend to have high affinity zinc transporters, capable of utilising low levels of zinc [87]. Certain species of clostridia have been shown to increase fermentation in response to additional zinc and the pathogenesis of clostridia difficile has been reported as being zinc dependent [88]. This is consistent with the consensus of opinion that the majority of zinc absorption occurs in the small intestine, leaving lower levels of zinc available for the colon and hence the microbiota situated there, possibly limiting the growth of certain species such as clostridia. Zinc deficiency has also been suggested as a risk factor in the development of Environmental Enteric Dysfunction (EDD) [89]. Impaired absorption of zinc leading to increased transit of zinc to the colon may alter the composition of gut microbiota going forward. Equally the impairment of immune function found with zinc deficiency may be directly impeding the ability of the intestinal epithelial cells, dendritic and T-regulatory cells' immune regulation mechanisms. In this regard zinc may be a risk factor for the development of unique pattern of microbiota in autism.

Given that the majority of dietary zinc is absorbed in the small intestine, it seems unlikely the principle cause of zinc deficiency is excessive consumption of zinc by the abnormal microbiota present in the colon. Perhaps colonisation in the small intestine occurs or perhaps certain microbes gaining a slight selective advantage for another reason have the capacity to alter zinc transporter expression or pancreatic function in a bid to improve carbohydrate, zinc and preferred nutrient transition to the large bowel. A similar mechanism may be behind the lower level of disaccharidases previously identified [90].

Chronic illness: Equally zinc deficiency is expected in chronic disease, and more so where bowel symptoms predominate $[85,87]$. Indeed, the non-ASD control group had a sub-normal 
mean zinc level $(11.67 \mu \mathrm{mol} / \mathrm{l}$ vs. the national average of $14.7 \mu \mathrm{mol} / \mathrm{l})$, presumably from the chronic illness they attended clinic for the more marked zinc deficiency identified in the ASDgroup $(10.01 \mu \mathrm{mol} / \mathrm{l})$ may simply relate to a more marked chronic disease state in the ASD group [87-91].

Physical co-morbidity: In adulthood the most likely cause of premature demise in ASD patients relates to seizure disorders with over 30 times increased risk of death from seizures regardless of co-existing intellectual disability [92]. Zinc deficiency has been explored as a risk factor for the development of seizures particularly intractable seizure disorders [93-95]. Cancer is another elevated risk for patients with ASD, and again there is evidence of increased risk through poor zinc status. It seems likely that poor zinc status will not only increase mortality rates in ASD, but also increase total morbidity and disease burden $[96,97]$. This remains to be proven as there have been no studies investigating the relationship between zinc status and the level of morbidity in ASD.

\section{Future Studies}

The results of this retrospective controlled analysis suggest further investigation into the relationship between zinc and autism may well be fruitful. A prospective controlled trial would enable improved data collection of both ASD patients and controls and mitigate any potential selection bias in those undergoing nutritional screening. Perhaps the most poignant question posed by this and other similar studies pertains to whether or not zinc supplementation prenatally, pre-paternally, maternally or in early infancy can provide any degree of protection over the eventual level of disability associated with autism or indeed perhaps even protect against it altogether in some cases. A population based longitudinal study of zinc levels during these periods may provide the crucial steer as to when zinc deficiency occurs and hence where in the pathophysiology of autism does zinc become key, and perhaps then when zinc supplementation may provide a useful harm-reduction intervention.

\section{Clinical Implications}

This study represents the largest controlled trial of serum zinc levels in ASD patients so far. To date, all studies exploring zinc status in ASD have demonstrated poor zinc status in ASD patients. Pending further investigations, clinicians should actively assess all patients with ASD, at diagnosis and throughout their life, for zinc deficiency. From the best available evidence, it is likely that adequate zinc status will reduce the burden of disease going forward. Supplementing zinc through a multi-vitamin is unlikely to be sufficient. Detailed analysis of the Cochrane

\section{References}

1 Landa RJ, Gross AL, Stuart EA (2013) Developmental trajectories in children with and without autism spectrum disorders: The first 3 years. Child Dev 84: 429-442.

2 Gotham K, Pickles A, Lord C (2012) Trajectories of autism severity reviews in this area reveal a loss of positive effect when zinc is given as part of a multi-vitamin formula and the authors could find no evidence multi-vitamins raise zinc levels [98-104]. Our results, whilst limited in number and detail of supplementation, suggest general supplementation alone is not adequate. Instead, oral zinc sulphate liquid titrated to serum response is recommended, preferably given in two divided doses daily. Clinicians should be aware of the potential impaired absorption of zinc caused by hypochlorhydria, small intestinal bacterial overgrowth, inflammatory bowel disease and excessive grain consumption, and hence failure for zinc deficiency to respond to oral zinc supplementation should prompt further investigation. As per tolerance, zinc should be administered away from meals containing grains, and additional vitamin $\mathrm{C}$ may improve absorption [105].

\section{Conclusion}

There have been a number of studies reporting zinc deficiency in ASD and the results of our moderately powered, controlled analysis support these findings. Indeed, $82 \%$ of patients with ASD were characterized as deficient, and there was a significant difference with controls $(P<0.001)$. Zinc deficiency appears common in autism and should be considered in all patients presenting with autism or early autism features. Our results also suggest poor zinc status in patients with autism may affect their immune function. Other studies have identified correlations between low or deficient zinc levels and neurological function in patients with autism. Whilst it remains unknown whether correct supplementation of zinc will reduce the severity of autism symptomology going forward, it is likely correction of zinc deficiency will reduce co-morbid illness and improve general health. Our recommendation is to be mindful of potential zinc deficiency in patients with autism and actively manage it when found. To help determine whether zinc deficiency is involved in the aetio-pathogenesis of autism, and therefore help determine if timely zinc supplementation can reduce the disease burden or even protect against the disability associated with ASD, a population based longitudinal study is required.

\section{Acknowledgements}

With great thanks to Biolab Medical Unit, London, for undertaking the nutrient analysis and facilitating the data collection.

\section{Funding}

With sincere gratitude to Hamish Mair for his timely, private donation towards this study.

in children using standardized ADOS scores. Pediatrics 130: e12781284.

3 Lord C, Luyster R, Guthrie W (2012) Patterns of developmental trajectories in toddlers with autism spectrum disorder. J Consult Clin Psychol 80: 477-489.

4 Jorde LB, Fineman RM, Martin RA (1983) Epidemiology and genetics 
of neural tube defects: An application of the Utah genealogical data base. Am J Phys Anthropol 62: 23-31.

5 Levy A, Perry A (2011) Outcomes in adolescents and adults with autism: A review of the literature. Res Autism Spectr Disord 5: 12711282.

6 Steffenburg S, Gillberg C, Hellgren L (1989) A twin study of autism in Denmark, Finland, Iceland, Norway and Sweden. J Child Psychol Psychiat 30: 405-416

7 Bailey A, Le Couteur A, Gottesman I (1995) Autism as a strongly genetic disorder: evidence from a British twin study. Psychol Med 25: 63-77.

8 Hallmayer J, Cleveland S, Torres A (2011) Genetic heritability and shared environmental factors among twin pairs with autism. Arch Gen Psychiatry 68: 1095-1102.

9 Gardener H, Spiegelman D, Buka SL (2009) Prenatal risk factors for autism: comprehensive meta-analysis. Br J Psychiatry 195: 7-14.

10 Calderón-Garcidueñas L, Mora-Tiscareño A, Ontiveros E (2008) Air pollution, cognitive deficits and brain abnormalities: A pilot study with children and dogs. Brain Cogn 68: 117-127.

11 Chen J-C, Schwartz J (2009) Neurobehavioral effects of ambient air pollution on cognitive performance in US adults. Neurotoxicol 30: 231-239.

12 Wang S, Zhang J, Zeng $X$ (2009) Association of traffic-related air pollution with children's neurobehavioral functions in Quanzhou, China. Environ Health Perspect 117: 1612-1618.

13 Freire C, Ramos R, Puertas R (2010) Association of traffic-related air pollution with cognitive development in children. J Epidemiol Community Health 64: 223-238.

14 Chiu Y-HM, Bellinger DC, Coull BA (2013) Associations between traffic-related black carbon exposure and attention in a prospective birth cohort of urban children. Environ Health Perspect 121: 859864.

15 Newman NC, Ryan P, Lemasters G (2013) Traffic-related air pollution exposure in the first year of life and behavioral scores at 7 years of age. Environ Health Perspect 121: 731-736.

16 Jedrychowski WA, Perera FP, Camann D (2014) Prenatal exposure to polycyclic aromatic hydrocarbons and cognitive dysfunction in children. Environ Sci Pollut Res 22: 3631-3639.

17 Lin CC, Yang SK, Lin KC (2014) Multilevel analysis of air pollution and early childhood neurobehavioral development. Int J Environ Res Public Health 11:6827-6841.

18 Sunyer J, Esnaola M, Alvarez-Pedrerol M (2015) Association between traffic-related air pollution in schools and cognitive development in primary school children: A prospective cohort study. Lanphear BP PLOS Med 12: e1001792.

19 Calderón-Garcidueñas L, Macías-Parra M, Hoffmann HJ (2009) Immunotoxicity and environment: immunodysregulation and systemic inflammation in children. Toxicol Pathol 37: 161-169.

20 Costa LG, Cole TB, Coburn J (2014) Neurotoxicants are in the air: Convergence of human, animal, and in vitro studies on the effects of air pollution on the brain. Biomed Res Int 2: 1-4.

21 Calderón-Garcidueñas L, D’Angiulli A, Kulesza RJ (2011) Air pollution is associated with brainstem auditory nuclei pathology and delayed brainstem auditory evoked potentials. Int J Dev Neurosci 29: 365375.
22 Krishnan RM, Sullivan JH, Carlsten C (2013) A randomized cross-over study of inhalation of diesel exhaust, hematological indices, and endothelial markers in humans. Part Fibre Toxicol 10: 7 .

23 Brook RD, Bard RL, Morishita M (2014) Hemodynamic, autonomic, and vascular effects of exposure to coarse particulate matter air pollution from a rural location. Environ Health Perspect 122: 624630.

24 GC W, Zhang L, Gunier R (2006) Autism spectrum disorders in relation to distribution of hazardous air pollutants in the San Francisco bay area. Env Heal Perspect 114: 1438-1444.

25 Kalkbrenner AE, Daniels JL, Chen JC, Poole C, Emch M, et al. (2010) Perinatal exposure to hazardous air pollutants and autism spectrum disorders at age 8. Epidemiol 21: 631-641.

26 HE V, Lurmann F, Penfold B (2012) Traffic-related air pollution, particulate matter, and autism. Arch Gen Psychiatry 2012: 1-7.

27 TA B, Wilhelm M, Olsen J (2012) Ambient air pollution and autism in Los Angeles County, California. Env Heal Perspect 121: 380-386.

28 AL R, Lyall K, JE H (2013) Perinatal air pollutant exposures and autism spectrum disorder in the children of nurses' health study II participants. Env Heal Perspect 121: 978-984.

29 CR J, YT L, BF H (2013) Air pollution and newly diagnostic autism spectrum disorders: A population-based cohort study in Taiwan. PLoS One 8: e75510.

30 Frassinetti S, Bronzetti G, Caltavuturo L (2006) The role of zinc in life: A review. J Environ Pathol Toxicol Oncol 25: 597-610.

31 Brayer KJ, Segal DJ (2008) Keep your fingers off my DNA: Proteinprotein interactions mediated by $\mathrm{C} 2 \mathrm{H} 2$ zinc finger domains. Cell Biochem Biophys 50: 111-131.

32 Haase H, Ober-Blöbaum JL, Engelhardt G (2008) Zinc signals are essential for lipopolysaccharide-induced signal transduction in monocytes. J Immunol 181: 6491-6502.

33 Takeda A, Tamano H (2009) Insight into zinc signalling from dietary zinc deficiency. Brain Res Rev 62: 33-44.

34 Varin A, Larbi A, Dedoussis G V (2008) In vitro and in vivo effects of zinc on cytokine signalling in human T cells. Exp Gerontol 43: 472482 .

35 Takeda A (2010) Insight into glutamate excitotoxicity from synaptic zinc homeostasis. Int J Alzheimers Dis 2011: 491597.

36 Lee DY, Prasad AS, Hydrick-Adair C (1993) Homeostasis of zinc in marginal human zinc deficiency: role of absorption and endogenous excretion of zinc. J Lab Clin Med 122: 549-556.

37 Hunt J, Gallagher S, Johnson L (1995) High- versus low-meat diets: effects on zinc absorption, iron status, and calcium, copper, iron, magnesium, manganese, nitrogen, phosphorus, and zinc balance in postmenopausal women. Am J Clin Nutr 62: 621-632.

38 Gibson S, Boyd A (2009) Associations between added sugars and micronutrient intakes and status: Further analysis of data from the National Diet and Nutrition Survey of Young People aged 4 to 18 years. Br J Nutr 101: 100-107.

39 Merialdi M, Caulfield LE, Zavaleta N (2004) Randomized controlled trial of prenatal zinc supplementation and the development of fetal heart rate. Am J Obstet Gynecol 190: 1106-1112.

40 Caulfield LE, Zavaleta N, Chen P (2011) Maternal zinc supplementation during pregnancy affects autonomic function of Peruvian children assessed at 54 months of age. J Nutr 141: 327-332. 
41 Merialdi M, Caulfield LE, Zavaleta N (1999) Adding zinc to prenata iron and folate tablets improves fetal neurobehavioral development. Am J Obstet Gynecol 180: 483-490.

42 Biadaioli R, Bandinelli R, Boddi V (1997) Zinc blood levels in 73 puerperal women. Correlation with obstetric and neonatal complications. Minerva Ginecol 49: 371375.

43 Tamura T, Goldenberg RL, Johnston KE (2000) Maternal plasma zinc concentrations and pregnancy outcome. Am J Clin Nutr 71: 109-113.

44 Ota E, Mori R, Middleton P (2015) Zinc supplementation for improving pregnancy and infant outcome. Cochrane database Syst Rev 2: CD000230.

45 Gogia S, Sachdev HS (2012) Zinc supplementation for mental and motor development in children. Cochrane database Syst Rev 12 CD007991.

46 Sazawal S, Bentley M, Black RE (1996) Effect of zinc supplementation on observed activity in low socioeconomic Indian preschool children. Pediatrics 98: 1132-1137.

47 Katz J, Khatry SK, Leclerq SC (2010) Daily supplementation with iron plus folic acid, zinc, and their combination is not associated with younger age at first walking unassisted in malnourished preschool children from a deficient population in rural Nepal. J Nutr 140: 13171321.

48 Keen CL, Gershwin ME (1990) Zinc deficiency and immune function. Annu Rev Nutr 10: 415-431.

49 Fraker PJ, King LE (2004) Reprogramming of the immune system during zinc deficiency. Annu Rev Nutr 24: 277-298.

50 Prasad AS (2007) Zinc: Mechanisms of host defense. J Nutr 137: 1345-1349.

51 Prasad AS (2009) Zinc: Role in immunity, oxidative stress and chronic inflammation. Curr Opin Clin Nutr Metab Care 12: 646-652.

52 Tuerk MJ, Fazel N (2009) Zinc deficiency. Curr Opin Gastroenterol 25: $136-143$.

53 Summersgill H, England H, Lopez-Castejon G (2014) Zinc depletion regulates the processing and secretion of $\mathrm{IL}-1 \beta$. Cell Death Dis 5 e1040.

54 Gower-Winter SD, Levenson CW (2008) Zinc in the central nervous system: From molecules to behavior. Biofactors 38: 186-193.

55 Prakash A, Bharti K, Majeed ABA (2015) Zinc: indications in brain disorders. Fundam Clin Pharmacol 29: 131-149.

56 Levenson CW, Morris D (2011) Zinc and neurogenesis: making new neurons from development to adulthood. Adv Nutr 2: 96-100.

57 Freedman LP, Luisi BF (1993) On the mechanism of DNA binding by nuclear hormone receptors: a structural and functional perspective. J Cell Biochem 51: 140-150.

58 O'Halloran TV (1993) Transition metals in control of gene expression. Science 261: 715-725.

59 Xie Z, Ma X, Ji W (2010) Zbtb20 is essential for the specification of CA1 field identity in the developing hippocampus. Proc Natl Acad Sci USA 107: 6510-6515.

60 Eckler MJ, McKenna WL, Taghvaei S (2011) Fezf1 and Fezf2 are required for olfactory development and sensory neuron identity. J Comp Neurol 519: 1829-1846.

61 Ren A, Zhang H, Xie Z (2012) Regulation of hippocampus-dependent memory by the zinc finger protein $\mathrm{Zbtb} 20$ in mature CA1 neurons.
Physiol 590: 4917-4932.

62 Halas ES, Hunt CD, Eberhardt MJ (1986) Learning and memory disabilities in young adult rats from mildly zinc deficient dams. Physiol Behav 37: 451-458.

63 Chowanadisai W, Kelleher SL, Lönnerdal B (2005) Maternal zinc deficiency reduces NMDA receptor expression in neonatal rat brain, which persists into early adulthood. J Neurochem 94: 510-519.

64 Wong CP, Rinaldi NA, Ho E (2015) Zinc deficiency enhanced inflammatory response by increasing immune cell activation and inducing IL6 promoter demethylation. Mol Nutr Food Res 59: $991-$ 999.

65 Summers BL, Henry CMA, Rofe AM (2008) Dietary zinc supplementation during pregnancy prevents spatial and object recognition memory impairments caused by early prenatal ethanol exposure. Behav Brain Res 186: 230-238.

66 Prasad AS, Beck FWJ, Bao B (2007) Zinc supplementation decreases incidence of infections in the elderly: effect of zinc on generation of cytokines and oxidative stress. Am J Clin Nutr 85: 837-844.

67 Kauppinen TM, Higashi Y, Suh SW (2008) Zinc triggers microglial activation. J Neurosci 28: 5827-5835.

68 Vargas DL, Nascimbene C, Krishnan C (2005) Neuroglial activation and neuroinflammation in the brain of patients with autism. Ann Neurol 57: 67-81.

69 Morgan JT, Chana G, Abramson I (2012) Abnormal microglialneuronal spatial organization in the dorsolateral prefrontal cortex in autism. Brain Res 1456: 72-81.

70 Tetreault NA, Hakeem AY, Jiang S (2012) Microglia in the cerebral cortex in autism. J Autism Dev Disord 42: 2569-2584.

71 Coyle P, Tran N, Fung JNT (2009) Maternal dietary zinc supplementation prevents aberrant behaviour in an object recognition task in mice offspring exposed to LPS in early pregnancy. Behav Brain Res 197: 210-218.

72 Kirsten TB, Galvão MC, Reis-Silva TM (2015a) Zinc prevents sickness behavior induced by lipopolysaccharides after a stress challenge in rats. PLoS One 10: e0120263.

73 Kirsten TB, Queiroz-Hazarbassanov N, Bernardi MM (2015b) Prenatal zinc prevents communication impairments and BDNF disturbance in a rat model of autism induced by prenatal lipopolysaccharide exposure. Life Sci 130: 12-17.

74 Omata Y, Salvador GA, Supasai S (2013) Decreased zinc availability affects glutathione metabolism in neuronal cells and in the developing brain. Toxicol Sci 133: 90-100.

75 Aimo L, Mackenzie GG, Keenan AH (2010) Gestational zinc deficiency affects the regulation of transcription factors AP-1, NF-KB and NFAT in fetal brain. J Nutr Biochem 21: 1069-1075.

76 Dvergsten CL, Fosmire GJ, Ollerich DA (1984) Alterations in the postnatal development of the cerebellar cortex due to zinc deficiency. II. Impaired maturation of Purkinje cells. Brain Res 318: 11-20.

77 Fatemi SH, Aldinger KA, Ashwood P (2012) Consensus paper: Pathological role of the cerebellum in autism. Cerebellum 11: 777807.

78 Malhotra A, Nair P, Dhawan DK (2011) Efficacy of zinc as a nutritional supplement in ameliorating chlorpyrifos-induced neurotoxicity in rats. J Environ Pathol Toxicol Oncol 30: 225-233. 
79 Bhalla P, Chadha VD, Dhar R (2007) Neuroprotective effects of zinc on antioxidant defense system in lithium treated rat brain. Indian $J$ Exp Biol 45: 954-958.

80 Brocardo PS, Assini F, Franco JL (2007) Zinc attenuates malathioninduced depressant-like behavior and confers neuroprotection in the rat brain. Toxicol Sci 97: 140-148.

81 Song $Y$, Xue $Y$, Liu X (2008) Effects of acute exposure to aluminum on blood-brain barrier and the protection of zinc. Neurosci Lett 445 42-46.

82 Adebayo OL, Adenuga GA, Sandhir R (2014) Postnatal protein malnutrition induces neurochemical alterations leading to behavioral deficits in rats: prevention by selenium or zinc supplementation. Nutr Neurosci 17: 268-278.

83 Prasanthi JRP, Hariprasad RG, Bhuvaneswari DC (2005) Zinc and calcium reduce lead induced perturbations in the aminergic system of developing brain. Biometals 18: 615-626.

84 Jaya PRP, Devi CB, Basha DC (2010) Calcium and zinc supplementation protects lead $(\mathrm{Pb})$-induced perturbations in antioxidant enzymes and lipid peroxidation in developing mouse brain. Int J Dev Neurosci 28: 161-167.

85 Gielda LM, DiRita VJ (2012) Zinc competition among the intestinal microbiota. MBio 3: e00171-212.

86 Vela G, Stark P, Socha M (2015) Zinc in gut-brain interaction in autism and neurological disorders. Neural Plast 2015: 972791.

87 Skrovanek S, DiGuilio K, Bailey R (2014) Zinc and gastrointestinal disease. World J Gastrointest Pathophysiol 5: 496-513.

88 Cafardi V, Biagini M, Martinelli M (2013) Identification of a novel zinc metalloprotease through a global analysis of Clostridium difficile extracellular proteins. PLoS One 8: e81306.

89 Lindenmayer GW, Stoltzfus RJ, Prendergast AJ (2014) Interactions between zinc deficiency and environmental enteropathy in developing countries. Adv Nutr 5: 1-6.

90 Williams BL, Hornig M, Buie T (2011) Impaired carbohydrate digestion and transport and mucosal dysbiosis in the intestines of children with autism and gastrointestinal disturbances. PLoS One 6: e24585.

91 Zhang WH, Wu XJ, Niu JX (2012) Serum zinc status and Helicobacter pylori infection in gastric disease patients. Asian Pac J Cancer Prev 13: 5043-5046.

92 Shavelle RM, Strauss DJ, Pickett J (2001) Causes of death in autism. J Autism Dev Disord 31: 569-576.
93 Russo AJ (2011) Analysis of copper and zinc plasma concentration and the efficacy of zinc therapy in individuals with Asperger's Syndrome, pervasive developmental disorder not otherwise specified (PDDNOS) and autism. Biomark Insights 6: 127-133.

94 Seven M, Basaran SY, Cengiz M (2013) Deficiency of selenium and zinc as a causative factor for idiopathic intractable epilepsy. Epilepsy Res 104: 35-39.

95 Saad K, Hammad E, Hassan AF (2014) Trace element, oxidant, and antioxidant enzyme values in blood of children with refractory epilepsy. Int J Neurosci 124: 181-186.

96 Gumulec J, Masarik M, Adam V (2014) Serum and tissue zinc in epithelial malignancies: A meta-analysis. PLoS One 9: e99790.

97 Li P, Xu J, Shi Y (2014) Association between zinc intake and risk of digestive tract cancers: a systematic review and meta-analysis. Clin Nutr 33: 415-420.

98 Yakoob MY, Theodoratou E, Jabeen A (2011) Preventive zinc supplementation in developing countries: Impact on mortality and morbidity due to diarrhea, pneumonia and malaria. BMC Public Health 11: S23.

99 Chung SH, Marzban H, Aldinger K (2011) Zac1 plays a key role in the development of specific neuronal subsets in the mouse cerebellum. Neural Dev 6: 25.

100 Kalkbrenner AE, Schmidt RJ, Penlesky AC (2014) Environmental Chemical Exposures and Autism Spectrum Disorders: A Review of the Epidemiological Evidence. Curr Probl Pediatr Adolesc Health Care 44: 277-318.

101 MMWR Surveill Summit (2014) Prevalence of autism spectrum disorder among children aged 8 years - Autism and developmental disabilities monitoring network, 11 sites, USA, 2010.

102 MMWR Surveill Summit (2012) Prevalence of autism spectrum disorders--Autism and Developmental Disabilities Monitoring Network, 14 sites, USA, 2008.

103 MMWR Surveill Summit (2009) Prevalence of autism spectrum disorders - Autism and Developmental Disabilities Monitoring Network, USA, 2006.

$104 \mathrm{Wu}$ YD, Xue C, Chen LJ (2013) Effect of zinc supplementation on acetone-butanol-ethanol fermentation by Clostridium acetobutylicum. J Biotechnol 165: 18-21.

105 Lakshmi Priya MD, Geetha A (2011) Level of trace elements (copper, zinc, magnesium and selenium) and toxic elements (lead and mercury) in the hair and nail of children with autism. Biol Trace Elem Res 142: 148-158. 